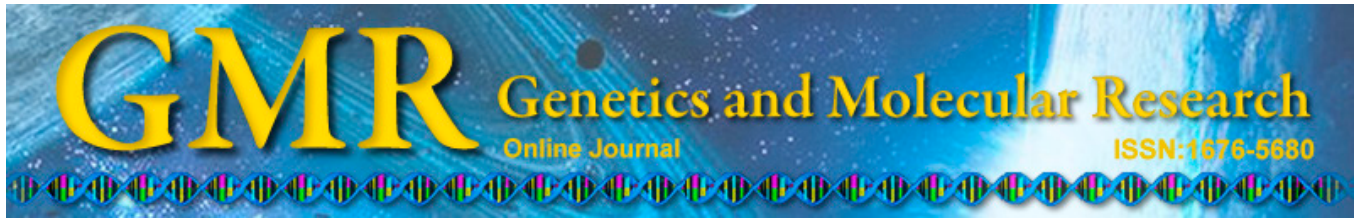

\title{
Effect of recombinant human endostatin on the expression of c-Myc and bFGF in mouse gastric cancer cells
}

\author{
Z.Y. Guo, G.D. Yao, L.P. Fu, Z.G. Fu and B. Hou \\ Department of Radiotherapy, Handan Central Hospital, \\ Affiliated Hospital of Hebei Medical University, Handan, Hebei, China \\ Corresponding author: G.D. Yao \\ E-mail: yaogendong@sina.com
}

Genet. Mol. Res. 14 (2): 5258-5265 (2015)

Received August 5, 2014

Accepted November 5, 2014

Published May 18, 2015

DOI http://dx.doi.org/10.4238/2015.May.18.17

\begin{abstract}
The aim of this study was to observe the effects of recombinant human endostatin on the proliferation and apoptosis of mouse gastric cancer cells, and explore some possible mechanisms of recombinant human endostatin inhibition of cancer. A murine gastric cancer xenograft model was established. A total of 20 mice were divided into two groups (control and experimental groups). The expression of c-Myc and basic fibroblast growth factor (bFGF) was determined by reverse transcription-polymerase chain reaction, Western blotting, and immunohistochemical staining methods. Tumor volume was measured and a growth curve was calculated. The tumor diameter in the experimental group was significantly smaller than that in the control group after treatment with endostatin for 21 days. The expression levels of c-Myc and $\mathrm{bFGF}$ in the experimental group were significantly lower than those of the control group $(\mathrm{P}<0.05)$. There was a positive correlation between the expression of c-Myc and bFGF in the experimental group. Microvessel density was significantly inhibited in the experimental group $(\mathrm{P}<0.05)$. These results demonstrated that recombinant human endostatin could inhibit tumor metastasis by inhibition of the expression of c-Myc and bFGF
\end{abstract}


in gastric cancer tissue as well as by inhibition of angiogenesis.

Key words: Recombinant human endostatin; Gastric cancer; c-Myc; bFGF; Tumor metastasis; Angiogenesis

\section{INTRODUCTION}

Gastric cancer is one of the most common malignant tumors in the gastrointestinal tract. Surgical removal is frequently used for gastric cancer at the early stage. Although treatments have shown continuous improvements, the recurrence and metastasis of gastric cancer lead to poor prognosis. Chemotherapy for advanced gastric cancer has been proven to be superior to the best supportive care in terms of survival and quality of life. Chemotherapy is mainly used in patients with early-stage gastric cancer to prevent recurrent tumors and metastasis (Murad et al., 1993; Glimelius et al., 1994; Pyrhönen et al., 1995).

The use of angiogenesis inhibitors for the treatment of cancer as a new approach is based on Folkman's theory from 1971 (Folkman, 1971). Endostatin inhibits tumor proliferation and metastases due to its role as a strong inhibitor of angiogenesis, and it is recommended for use in combination with chemotherapy, radiotherapy, or biotherapy (O'Reilly et al., 1997; Xu et al., 2007). Recombinant human endostatin has been well studied as an endogenous antiangiogenic peptide that has multiple antitumor roles through modulation of various receptors in the plasma membrane, such as suppression of angiogenesis and inhibition of tumor-cell migration and invasion (Folkman, 2002, 2006; Zhuang and Yuan, 2009). Use of the novel recombinant human endostatin Endostar, combined with chemotherapy for lung, breast, and gastric cancer, as well as melanoma and other tumors, is more effective than single chemotherapy (Han et al., 2011; Cui et al., 2013).

In this study, we evaluated the effect of recombinant human endostatin on the proliferation and apoptosis of mouse gastric cancer cells, and explored some possible mechanisms of recombinant human endostatin inhibition of cancer.

\section{MATERIAL AND METHODS}

\section{Experimental animals}

A total of 20 specific pathogen-free male mice weighing 18-20 g were obtained from the animal experimental center of Hebei Province. These mice were kept in a clean and quiet environment with a room temperature of $22^{\circ} \pm 1^{\circ} \mathrm{C}$ and relative humidity at $40-50 \%$. The mice had free access to food and drinking water and allowed to acclimate to the environment prior to experimental initiation. Cages, food, and drinking water were changed regularly.

Mouse fore-stomach carcinoma (MFC) cells were obtained from the American Type Culture Collection (Manassas, VA, USA). They were cultured at $37^{\circ} \mathrm{C}$ with $5 \% \mathrm{CO}_{2}$, and 0.2 $\mathrm{mL}$ MFC cell suspension $\left(10^{7}\right.$ cells $\left./ \mathrm{mL}\right)$ was inoculated into the mouse right armpit under sterile conditions. The mice were randomly divided into two groups (control and experimental). Each group contained 10 mice. The mice in the experimental group were treated with $0.8 \mathrm{mg} /$ $\mathrm{kg}$ recombinant human endostatin via intraperitoneal injection for 14 days. The mice in the control group were treated with intraperitoneal injection of saline for 14 days.

Housing and procedures involving experimental animals were in accordance with the 
Guide for the Care and Use of Laboratory Animals (National Research Council (US) Committee for the Update of the Guide for the Care and Use of Laboratory Animals, 2011). All experimental procedures were approved by the Care of Experimental Animals Committee of our hospital.

\section{General observations}

Each morning the mice were observed for state of mind, body shape, physical activity, and reactivity, and any abnormal conditions were recorded. The tumor volumes of mice were measured and calculated with a Vernier caliper every 3 days. The inhibition rate of tumor volume was calculated by: (mean volume of control group - mean volume of experimental group) / mean volume of control group) x 100\%.

\section{Immunohistochemical detection of c-Myc, CD34, and basic fibroblast growth factor (bFGF) expression}

Briefly, the transplanted tumor specimens were taken from the animals at 21 st day and fixed in $10 \%$ formaldehyde, then they were removed from fixative and washed, and paraffinembedded with an automatic embedding machine. The embedded specimens were sliced at a thickness of $4 \mu \mathrm{m}$. Following deparaffinization, dehydration, and antigen retrieval, the sections were blocked with $5 \%$ bovine serum albumin and incubated at $37^{\circ} \mathrm{C}$ for $20 \mathrm{~min}$, and then incubated with 1:200 diluted mouse anti human c-Myc, CD34, and bFGF antibodies (antibodies-online Inc., Atlanta, GA, USA) at $4^{\circ} \mathrm{C}$ overnight. After incubation, they were washed with phosphate-buffered saline and incubated at $37^{\circ} \mathrm{C}$ in a water bath for $2 \mathrm{~h}$ after drop-adding the 2nd antibody (IHC HRP detection kit; Invitrogen, USA) and washed with phosphatebuffered saline. After treatment with DAB solution, sections were flushed completely, counterstained with hematoxylin, washed with water, treated with dehydration and transparency agents, mounted on slides, then observed under a microscope (DMLA, Leica Inc., Germany) and analyzed with the Qwin software (v2.3, Leica Inc., Germany).

\section{Detection of the expression of $c-M y c$ and $b F G F$ mRNA with reverse transcription -polymerase chain reaction (RT-PCR) amplification}

The total RNA of transplanted tumor specimens was extracted with an RNA Isolation Kit (Promega (Beijing) Biotech Co., Ltd., Beijing, China) according to the manual. The process of reverse transcription was conducted using PrimeScript 1st-Strand cDNA Synthesis Kit (TaKaRa Biotech (Dalian) Co., Ltd., Dalian, China). The primers for PCR were as follows: $c-M y c$-F: 5'-CCT AGT GCT GCA TGA GGA GAC AC-3', $c-M y c-R:$ 5'-TCC ACA GAC ACC ACA TCA ATT TCT T-3'; $b F G F-F$ : 5'-GTC ACG GAA ATA CTC CAG TTG GT-3', $b F G F$ R: 5'-CCG TTT TGG ATC CGA GTT TAT ACT-3'; Gapdh-F: 5'-CCG AGA ATG GGA AGC TTG TC-3', Gapdh-R: 5'-TTC TCG TGG TTC ACA CCC ATC-3'. The procedure for the PCR was as following: predegeneration for $5 \mathrm{~min}$ at $94^{\circ} \mathrm{C}$; degeneration for $30 \mathrm{~s}$ at $94^{\circ} \mathrm{C}$, annealing for $30 \mathrm{~s}$ at $55^{\circ} \mathrm{C}$, extension for $30 \mathrm{~s}$ at $72^{\circ} \mathrm{C}$ for 30 cycles, and amplification extension for 10 min at $72^{\circ} \mathrm{C}$. The PCR product was analyzed by $1 \%$ agarose gel electrophoresis $(5 \mathrm{~V} / \mathrm{cm} \times 30$ $\mathrm{min}$ ); photos were taken. We measured the background intensity of a gray area on the gel image to calculate the ratio of c-Myc/ Gapdh and bFGF/Gapdh using the Quantity One software (v4.62, Bio-Rad, USA), which represented the relative mRNA level. 


\section{Detection of the expression of c-Myc and bFGF protein with Western blotting}

Briefly, the total proteins of transplanted tumor specimens were isolated and the protein concentrations were determined using the Bradford protein assay. Total proteins were separated by $12 \%$ sodium dodecyl sulfate polyacrylamide gel electrophoresis, and were transferred to polyvinylidene difluoride membranes (Millipore Co., Billerica, MA, USA). The membranes were blocked with $5 \%$ non-fat milk in TBST $(10 \mathrm{mM}$ Tris- $\mathrm{HCl}, \mathrm{pH} 8.0,150 \mathrm{mM}$ $\mathrm{NaCl}$, and $0.1 \%$ Tween-20) for $2 \mathrm{~h}$, then incubated with the primary antibodies: mouse antihuman c-Myc or bFGF monoclonal antibodies (antibodies-online Inc.), at $4^{\circ} \mathrm{C}$ overnight. Following incubation, membranes were incubated with secondary antibodies (IHC HRP detection kit) at room temperature for $1 \mathrm{~h}$. Photos were taken and the background intensity of a gray area on the gel image was measured to calculate the ratio of c-Myc/Gapdh and bFGF/Gapdh using the Quantity One software (v4.62).

\section{Determination of microvessel density (MVD)}

Tumor sections (the same fixed sections utilized for immunohistochemistry) were stained using mouse anti-human CD34 monoclonal antibody (antibodies-online Inc.). The anti-CD34staining region was observed at low magnification (40X), and then the CD34-positive-staining vessels were counted under high magnification (400X) to determine vascular number.

\section{Statistical analysis}

Statistical analysis was performed using the Statistical Package for the Social Science (SPSS, version 17.0) software (SPSS, Chicago, IL, USA). Spearman correlation, the Student $t$-test, the $\chi^{2}$ test, exact probability, and rank correlation analyses were used. $\mathrm{P}<0.05$ was considered to be significant.

\section{RESULTS}

\section{Behavioral changes in mice}

The mice in the two groups showed similar activities before treatment. However, the mice in the control group had poor spirit, reduced water consumption, and were increasingly unresponsive and inactive as the number of tumor nodules increased. No obvious adverse reaction to the experimental protocol was observed in the experimental group.

\section{Changes of tumor volume}

The mice in the two groups had similar tumor volumes before treatment $(\mathrm{P}>0.05)$. The tumor volume of the mice in the control group gradually increased and reached 1085.6 \pm $124.8 \mathrm{~mm}^{3}$ at 21 days after treatment. The tumor volume of the mice in the experimental group reached the maximum at 9 days after treatment and then gradually decreased. The inhibition rate of tumor volume was $72.89 \%$. The tumor volume of the mice in the experimental group was significantly smaller than that in the control group after treatment for 9 days $(\mathrm{P}<0.05$; Figure 1). 


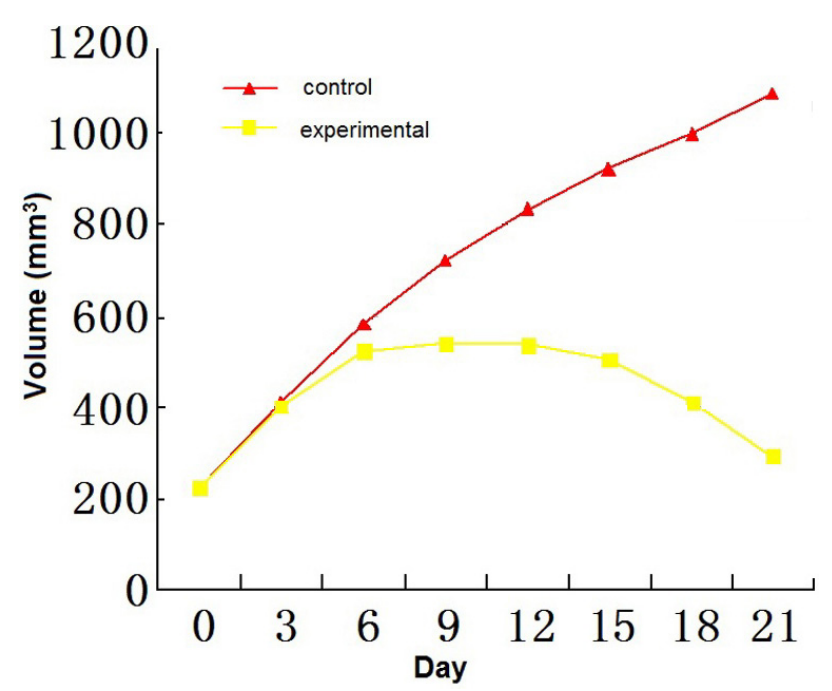

Figure 1. Changes of tumor volume in the two groups.

\section{Immunohistochemical detection of the expression of c-Myc and bFGF}

The average background gray value of the experimental group was significantly higher than that of the control group $(\mathrm{P}<0.05)$, and staining intensity of positive cells for bFGF and c-Myc in the experimental group was significantly lower than that of the control group $(\mathrm{P}<0.05$; Table 1$)$.

\begin{tabular}{|c|c|c|c|c|c|}
\hline \multirow[t]{2}{*}{ Group } & \multirow[t]{2}{*}{$\mathrm{N}$} & \multicolumn{2}{|c|}{ c-Myc } & \multicolumn{2}{|c|}{ bFGF } \\
\hline & & Positive cells & Average gray value & Positive cells & Average gray value \\
\hline Control & 10 & $98.1 \pm 1.5$ & $34.8 \pm 3.8$ & $84.2 \pm 4.2$ & $53.9 \pm 8.9$ \\
\hline Experimental & 10 & $54.4 \pm 5.8^{*}$ & $72.5 \pm 14.2 *$ & $57.3 \pm 7.1^{*}$ & $71.4 \pm 12.6^{*}$ \\
\hline
\end{tabular}

*Compared with control, $\mathrm{P}<0.05$.

\section{RT-PCR detection of $c-M y c$ and $b F G F$ mRNA expression}

The expression of $b F G F$ and $c-M y c$ mRNA of the experimental group was significantly lower than that of control group $(\mathrm{P}<0.05$; Table 2$)$.

Table 2. Comparison of the expression of $c-M y c$ and $b F G F$ mRNA in the two groups by reverse transcriptionpolymerase chain reaction.

\begin{tabular}{lccc}
\hline Group & $\mathrm{N}$ & $\mathrm{c}-\mathrm{Myc}$ & bFGF \\
\hline Control & 10 & $1.6 \pm 0.5$ & $2.3 \pm 0.6$ \\
Experimental & 10 & $1.1 \pm 0.3^{*}$ & $1.2 \pm 0.3^{*}$ \\
\hline
\end{tabular}

*Compared with control, $\mathrm{P}<0.05$. 


\section{Detection of the expression of c-Myc and bFGF protein by Western blotting}

The expression of bFGF and c-Myc protein in the experimental group was significantly lower than that in the control group $(\mathrm{P}<0.05$; Table 3$)$.

\section{Table 3. Comparison of the expression of c-Myc and bFGF in the two groups by Western blotting.}

\begin{tabular}{lccc}
\hline Group & $\mathrm{N}$ & $\mathrm{c}-\mathrm{Myc}$ & $\mathrm{bFGF}$ \\
\hline Control & 10 & $83.6 \pm 8.9$ & $87.9 \pm 11.3$ \\
Experimental & 10 & $65.7 \pm 6.7^{*}$ & $54.5 \pm 6.5^{*}$ \\
\hline
\end{tabular}

*Compared with control, $\mathrm{P}<0.05$.

\section{Changes of MVD}

MVD was significantly inhibited in the experimental group $(\mathrm{P}<0.05$; Table 4).

Table 4. Comparison of microvessel density (MVD) in the two groups.

\begin{tabular}{lcc}
\hline Group & $\mathrm{N}$ & MVD \\
\hline Control & 10 & $9.2 \pm 1.3$ \\
Experimental & 10 & $2.9 \pm 1.0^{*}$ \\
\hline
\end{tabular}

*Compared with control, $\mathrm{P}<0.05$.

\section{Correlation analysis of c-Myc and bFGF expression}

There was a positive correlation between the expression of c-Myc and bFGF ( $\mathrm{r}=$ $0.863, \mathrm{P}=0.006$ ) across the whole study.

\section{DISCUSSION}

Recombinant human endostatin is a type of anti-tumor molecular-targeted drug. It has been confirmed that endostatin can specifically inhibit the proliferation of vascular endothelial cells and tumor angiogenesis (Facemire et al., 2009; You et al., 2010; Choueiri et al., 2011). $\mathrm{c}-\mathrm{Myc}$ is an oncogene that has been shown to play an important role in the cell cycle, angiogenesis, cellular metabolism, cellular adhesion, and apoptosis (Oster et al., 2003). Its primary roles of promotion of cellular proliferation and inhibition of cellular differentiation cause the cells in which it is expressed abnormally to undergo malignant transformation (Oster et al., 2002; Hurlin and Dezfouli, 2004). Overexpression of c-Myc has been reported in many kinds of human tumor tissues (Oster et al., 2002; Yekkala and Baudino, 2007).

bFGF is a member of the fibroblast growth factor family (Kim, 1998), and is an important regulator of cellular growth, differentiation, and angiogenesis. bFGF is involved in the process of tumor formation, and in wound healing in both normal tissues and during tumor development. The action of heparan sulfate-degrading enzymes activates bFGF, thus mediating the formation of new blood vessels (Flamme et al., 1997; Kühn et al., 2012). bFGF has been shown in preliminary animal studies to protect the heart from injury associated with a heart attack, 
reducing tissue death, and promoting improved function after reperfusion (House et al., 2003).

In this study, we found that the tumor volume of the mice in the control group gradually increased until they reached the maximum volume at 9 days after treatment, and then gradually decreased in the experimental group only. Therefore, we conjectured that recombinant human endostatin could inhibit tumor proliferation and metastasis by inhibition of tumor angiogenesis. MVD is an important marker for determining the degree of tumor angiogenesis. We found that MVD was significantly inhibited in the experimental group in this study. This result confirmed that recombinant human endostatin had an obvious effect on angiogenesis. In this study we also found that the expression of bFGF and c-Myc in the experimental group was significantly lower than that in the control group. These results suggested that endostatin has the potential for wide application in anti-tumor treatment. There were no obvious adverse reactions such as bleeding following recombinant human endostatin treatments. In conclusion, this study confirmed that endostatin could inhibit the expression of c-Myc and bFGF, reduce the MVD of tumor tissues and therefore demonstrated efficacy as an anti-tumor treatment.

\section{ACKNOWLEDGMENTS}

Research supported by a grant from the Natural Science Research Project of Hebei Province (\#300328).

\section{REFERENCES}

Choueiri TK, Mayer EL, Je Y, Rosenberg JE, et al. (2011). Congestive heart failure risk in patients with breast cancer treated with bevacizumab. J. Clin. Oncol. 29: 632-638.

Cui C, Mao L, Chi Z, Si L, et al. (2013). A phase II, randomized, double-blind, placebo-controlled multicenter trial of Endostar in patients with metastatic melanoma. Mol. Ther. 21: 1456-1463.

Facemire CS, Nixon AB, Griffiths R, Hurwitz H, et al. (2009). Vascular endothelial growth factor receptor 2 controls blood pressure by regulating nitric oxide synthase expression. Hypertension 54: 652-658.

Flamme I, Frölich T and Risau W (1997). Molecular mechanisms of vasculogenesis and embryonic angiogenesis. J. Cell. Physiol. 173: 206-210.

Folkman J (1971). Tumor angiogenesis therapeutic implications. N. Eng. J. Med. 285: 1182-1186.

Folkman J (2002). Role of angiogenesis in tumor growth and metastasis. Semin. Oncol. 29: 15-18.

Folkman J (2006). Antiangiogenesis in cancer therapy - endostatin and its mechanisms of action. Exp. Cell Res. 312: 594-607.

Glimelius B, Hoffman K, Haglund U, Nyrén O, et al. (1994). Initial or delayed chemotherapy with best supportive care in advanced gastric cancer. Ann. Oncol. 5: 189-190.

Han B, Xiu Q, Wang H, Shen J, et al. (2011). A multicenter, randomized, double-blind, placebo-controlled study to evaluate the efficacy of paclitaxel-carboplatin alone or with endostar for advanced non-small cell lung cancer. $J$. Thorac. Oncol. 6: 1104-1109.

House SL, Bolte C, Zhou M, Doetschman T, et al. (2003). Cardiac-specific overexpression of fibroblast growth factor-2 protects against myocardial dysfunction and infarction in a murine model of low-flow ischemia. Circulation 108: 3140-3148.

Hurlin PJ and Dezfouli S (2004). Functions of myc: max in the control of cell proliferation and tumorigenesis. Int. Rev. Cytol. 238: 183-226.

Kim HS (1998). Assignment1 of the human basic fibroblast growth factor gene FGF2 to chromosome 4 band q26 by radiation hybrid mapping. Cytogenet. Cell Genet. 83: 73.

Kühn MC, Willenberg HS, Schott M, Papewalis C, et al. (2012). Adipocyte-secreted factors increase osteoblast proliferation and the OPG/RANKL ratio to influence osteoclast formation. Mol. Cell Endocrinol. 349: 180-188.

Murad AM, Santiago FF, Petroianu A, Rocha PR, et al. (1993). Modified therapy with 5-fluorouracil, doxorubicin, and methotrexate in advanced gastric cancer. Cancer 72: 37-41.

National Research Council (US) Committee for the Update of the Guide for the Care and Use of Laboratory Animals (2011). Guide for the Care and Use of Laboratory Animals. 8th edn. National Academies Press, Washington (DC). 
O’Reilly MS, Boehm T, Shing Y, Fukai N, et al. (1997). Endostatin: an endogenous inhibitor of angiogenesis and tumor growth. Cell 88: 277-285.

Oster SK, Ho CS, Soucie EL and Penn LZ (2002). The myc oncogene: MarvelouslY Complex. Adv. Cancer Res. 84: $81-154$.

Oster SK, Mao DY, Kennedy J and Penn LZ (2003). Functional analysis of the N-terminal domain of the Myc oncoprotein. Oncogene 22: 1998-2010.

Pyrhönen S, Kuitunen T, Nyandoto P and Kouri M (1995). Randomised comparison of fluorouracil, epidoxorubicin and methotrexate (FEMTX) plus supportive care with supportive care alone in patients with non-resectable gastric cancer. Br. J. Cancer 71: 587-591.

Xu F, Ma Q and Sha H (2007). Optimizing drug delivery for enhancing therapeutic efficacy of recombinant human endostatin in cancer treatment. Crit. Rev. Ther. Drug Carrier Syst. 24: 445-492.

Yekkala K and Baudino TA (2007). Inhibition of intestinal polyposis with reduced angiogenesis in ApcMin/+mice due to decreases in c-Myc expression. Mol. Cancer Res. 5: 1296-1303.

You ZY, Zhao Y, Liu F, Zhang YD, et al. (2010). The radiosensitization effects of Endostar on human lung squamous cancer cells H-520. Cancer Cell Int. 10: 17.

Zhuang HQ and Yuan ZY (2009). Process in the mechanisms of endostatin combined with radiotherapy. Cancer Lett. 282: 9-13. 